\title{
Using a Project to Link Introduction to Engineering, Freshman Composition, and Pre-Calculus for Entering Engineering Students
}

\author{
Walter W. Fisher, Connie Kubo Della-Piana, Carol Crowley \\ University of Texas at El Paso
}

\section{INTRODUCTION}

\section{The University}

The University of Texas at El Paso (UTEP) is a comprehensive public urban institution. As a mid-size, commuter campus located in the world's largest binational metropolitan center, the University of Texas at El Paso is recognized as one of the nation's most successful educators of Hispanic students. Over 60 percent of its approximately 15,000 students are under-represented minorities; an estimated two-thirds of them are the first in their families to attend college.

In the last two decades, UTEP has developed and sustained major institutional change initiatives and curricular reform to meet the needs of the region's students. The driving force has been and continues to be the development of institutional structures and processes that increase the involvement of students who are less-affluent, work outside the university, have substantial family obligations, and/or are less prepared for college than students who attend small private residential colleges. UTEP is committed to recruiting and educating the region's students and helping them compete successfully on a global scale. As a consequence, it has become the only major urban university in the Southwest whose student body matches the demographics of the region it serves.

\section{UTEP's Evolving Cluster Program}

Based on its record of dedication to and success in serving historically under-represented populations, the National Science Foundation awarded the University of Texas at El Paso a Model Institutions for Excellence (MIE) grant. The MIE initiative is a groundbreaking program that supports colleges and universities in their efforts to become models for improving the quantity and quality of science, engineering, and mathematics (SEM) graduates.

A major element in UTEP's design and implementation of its model has involved the development and establishment of the "cluster" program or powerful learning communities for the benefit of beginning SEM students who are not calculus ready, and therefore, not qualified to begin the standard engineering or science undergraduate programs. "Clustering" involves placing students in cohorts and scheduling them to attend the same blocked and linked courses that integrate subject matter across courses. Each "cluster" of courses includes (1) either Introduction to Engineering and Physical Science or Introduction to Biology, (2) a module-based class in precalculus, and (3) a first-year English composition class designed to integrate English with 
engineering or biology and mathematics.

The program is designed to meet the specific curricular and social needs of entering preengineering and pre-science students. In the past these students had no department, program of study, or departmental advisor. The program is, in a sense, an "academic home" for pre-science and pre-engineering students who are not able to matriculate into a program of study. The cluster program is designed to provide students with an opportunity to:

- Establish close relationships with faculty who are teaching one of the linkblocked courses in the cluster program;

- Make new friends who have interests in similar disciplines;

- Develop study groups and a culture of persistence;

- Connect with others who could socialize students into the university community;

- Participate in academic and social activities that encourage "best effort;"

- Provide feedback for the continuous improvement of the program.

The cluster courses incorporate cooperative learning as a pedagogical strategy for increasing student learning and success in the courses. Faculty in each of the cluster courses implement cooperative elements based on the needs of the students, the structure of the subject matter and activities, and the knowledge of the instructor. Starting with the Fall 1997 semester, peer undergraduate facilitators were present in the classrooms of the cluster sections and assisted the instructor with the group work. Student teams formed in the math courses are kept intact in the other courses that make up the "cluster."

\section{A Common Cluster Project}

Most science and engineering students do not realize the importance of math and, especially, written communication to their success, first as students, and then, as professionals. The cluster program offered an opportunity to show beginning students how math supports their chosen discipline and to demonstrate how effective communication can help them to be better engineers and scientists. This was accomplished in part by developing a common project on a single topic that included data analysis, problem solving, critical thinking, and writing as illustrated in figure 1. The project was introduced in the Introduction to Physical Science and Engineering course. Work done on the project in each course was combined to create a final report in the engineering course. The goals of the common project were:

- to strongly link math and English to engineering in the three course cluster,

- to demonstrate the multi-disciplinary nature of real problems,

- to insure that all students understood all of the issues of the project topic,

- to promote critical thinking,

- to improve writing skills,

- to provide students with practical math applications, and

- to demonstrate the importance of written communication in engineering. 


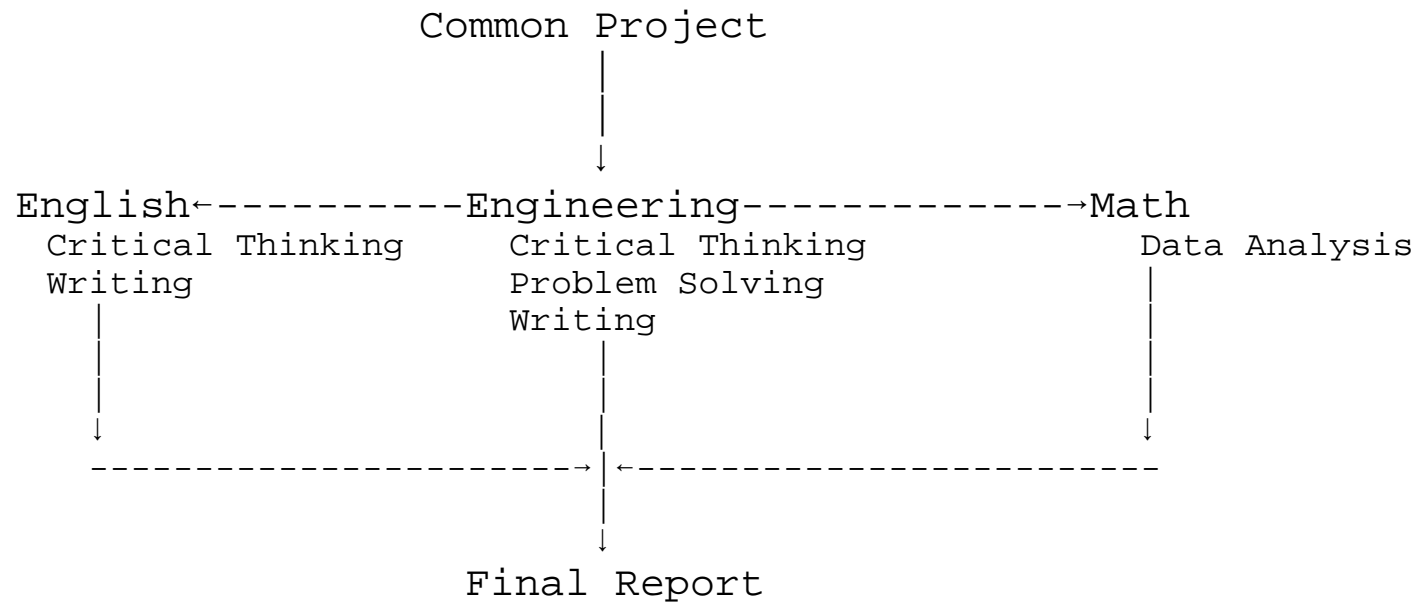

Figure 1. Connecting engineering, math and English through a common project.

\section{THE COMMON PROJECT PILOT}

\section{Student Profile}

The students in the cluster program are all entering students experiencing their first semester at the university. They are probably very similar in their background to entering students at other comprehensive public urban universities. The profile developed to help cluster faculty understand these students includes the following characteristics.

First in family to attend college

Weak math background

Underdeveloped communication skills

Poor learning skills

Poor time management skills

Underdeveloped critical thinking skills
Unfocused career and life goals

Minimal time spent on campus

Don't develop support groups

Low self-confidence

Poor social skills

Poor use of university resources

In general, entering students do not perceive themselves as having most of these deficiencies. They have to be carefully led to the realization that they need help to prepare themselves to succeed at the university.

\section{Project Requirements}

The requirements agreed upon for the common project topic were:

- It must be complex enough to allow development of critical thinking skills. 
- It must be controversial so that it simulates discussion and leads to an open-ended solution.

- It must provide numerical data for analysis.

- It must have some connection to science and engineering.

- Information on the topic must be readily available.

\section{Preparation}

A list of several potential topics was assembled for consideration by the three instructors in one of the engineering clusters. A preliminary literature search was done on each topic to determine the availability of information in the UTEP library. A wide variety of articles was identified for each topic, but it was discovered that most of the them would need to be acquired through interlibrary loans. The topic chosen for the pilot common project was "withdrawal of public land from logging in the Pacific Northwest." This topic met the first four requirements and one of the instructors had used it on and off since 1989 in the calculus-based Introduction to Engineering course as a term paper project. Since one of the goals for the common project was that each student in the cluster classes understand all of the issues, it was decided that most of the information would be provided to the students in a reading packet instead of requiring them to perform their own literature search.

A student assistant spent most of the summer completing the literature search on the project topic and collecting the articles, most of which had to be ordered through interlibrary loan. The engineering instructor reviewed all of the articles and selected sixteen that covered most of the issues. These were then shared with the English instructor for her approval. The articles (Illustration 1) were then copied to create reading packets for the students.

\section{The Engineering Connection}

Pre-engineering students placing into the pre-calculus course are one to two semesters away from taking the first calculus course and being able to take courses in the engineering curriculum. The two primary academic barriers for pre-engineering students have been passing the pre-calculus course, and because they are not yet in an engineering program, maintaining their interest in engineering. The Introduction to Physical Science and Engineering course, which can not be counted toward an engineering degree, was designed to help pre-engineering students succeed in the pre-calculus course and to develop a foundation for success at the university. Topics included in the course are learning skills, problem solving, math applications in engineering, use of the TI-85 calculator (required in all math through calculus), computer literacy, library research skills, and report writing. The lab focuses on science and engineering projects. The common project provided a means to develop a strong link with English and math.

To give the project a realistic nature, the students were told that they worked in the office of a U.S. Senator as a technical assistant. The project was assigned to them through a memorandum from the Senator's executive assistant. Each student received a memo addressed specifically to them as shown in illustration 2. They were instructed to write a memo to the executive assistant 
to report progress on their research each week.

$-5-$

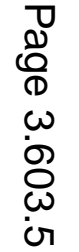




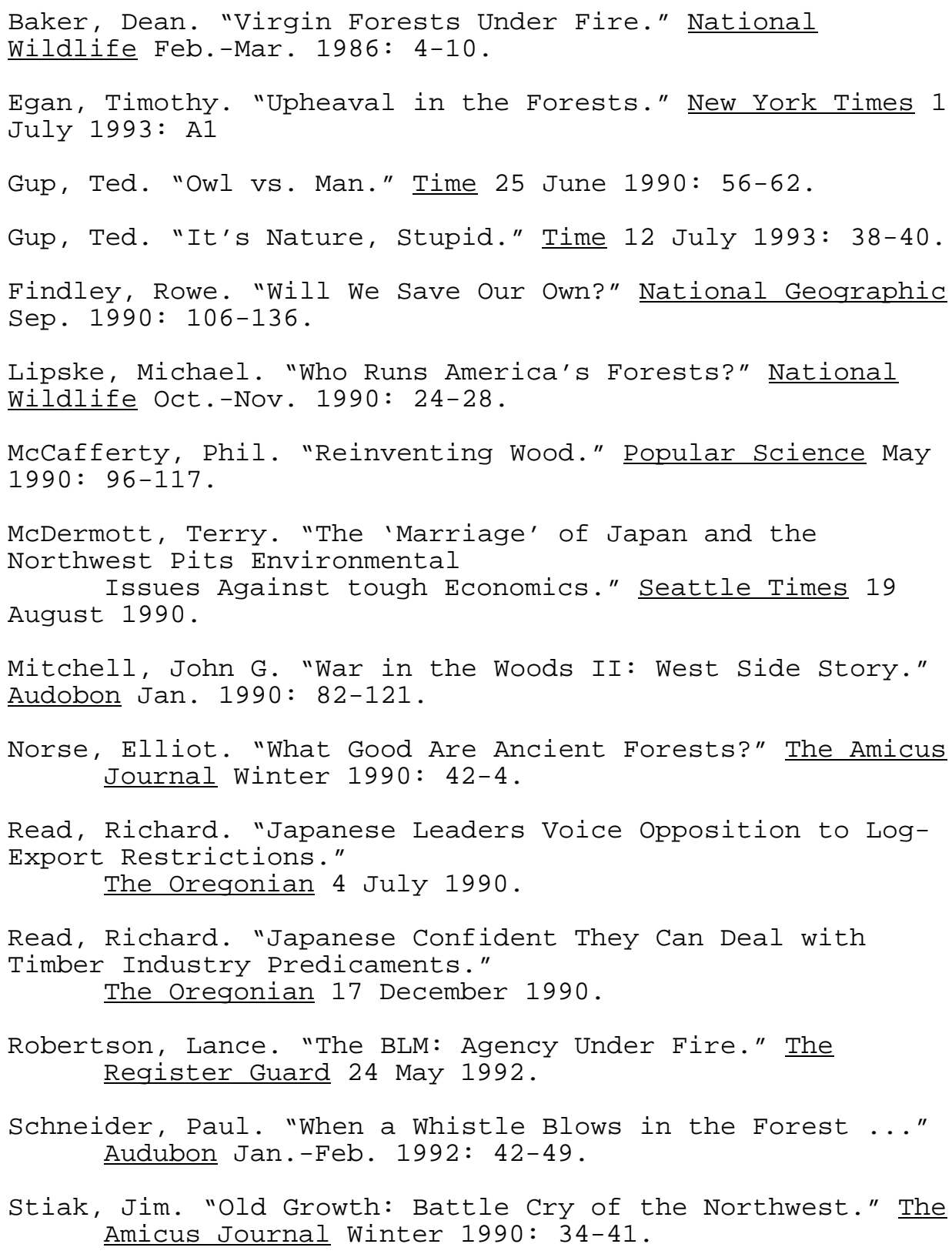

Illustration 1. Articles in the reading packet for the Pacific Northwest Project. 
In order to help the students gain an understanding of all the issues, the project was broken into the following seven modules.

- Who "owns" public land?

- What are the potential consequences of a logging ban?

- What are the potential consequences of continued logging?

- What about new wood technology and wood substitutes?

- Who controls the use of public land?

- What is the role of the northern spotted owl?

- What is the role of Japan?

The project was assigned in the third week of classes. A module was covered each week for the next seven weeks. Reading for each module was assigned the week before the module was to be covered. On Monday the students came prepared to discuss with their group what they had learned in their reading. Most of the class period (about 45 minutes) was allowed for group discussion. Each student then prepared a memo for the Senator's executive assistant summarizing his or her understanding of the module topic. The memos were turned in on Wednesday. The instructor edited and critiqued the memos and prepared a handout summarizing all the ideas presented by the students. The graded memorandums and the summary of ideas was returned to the students on Friday. A few minutes of class time were then used to make sure all of the students understood the issues in the module.

The only topic that the students were required to research on their own was new wood technology and wood substitutes. Each student was required to complete a literature search and obtain copies of two articles. All of the articles found by the students were then shared with the class.

After all the modules for the project had been covered in the engineering course, the students began preparation of the briefing paper for the Senator. A minimum of three drafts of the paper were required. The first draft was edited and critiqued by the peer facilitator/tutor for the English class. Some students submitted several drafts to the peer facilitator. The second draft was reviewed and critiqued by the English instructor. Finally, the completed paper with a cover memo transmitting it to the Senator was submitted to the Engineering instructor.

One of the critical issues that may come to a vote in January 1998 is the withdrawal of all Northwestern U.S. public forest lands from lease to the lumber industry. Senator Henderson has been swamped with calls from environmentalists, lumber company executives and lobbyists, lumber worker union representatives, individual lumberjacks, and local government officials, each presenting his side of the issue. The senator is particularly concerned because some environmentalists have told him that there is no need to cut big trees to get large pieces of wood any longer. New processes can use small, rapidly grown trees to make any size of "wood" piece. Another group has claimed that most of the really old, large trees are not being used in the U.S., but are being sold to Japan at a high profit. On the other hand, lobbyists for the lumber industry and local government officials in the Pacific Northwest are threatening large layoffs of people and 


\section{Office of the Honorable Carl T. Henderson Senator \\ Texas}

\section{MEMORANDUM}

TO: $\quad$ Brooke Nowak, Technical Assistant

FROM: $\quad$ Jack R. Davenport, Executive Assistant

DATE: $\quad$ September 22, 1997

SUBJECT: Logging ban on public lands in the Pacific Northwest

Research the issues and prepare a briefing paper for Senator Henderson that provides a background on all of the issues in this controversy and makes a recommendation for the "best" solution to the problem. Since the Senator needs this information before the Thanksgiving recess, please complete this assignment by November 26, 1997. Report your progress to me by memo on a weekly basis.

Illustration 2. Memorandum assigning the Pacific NW project.

shortages of lumber if the source of trees is cut off.

\section{The English Connection}

The English composition course is the first of two courses required for all university students. Consequently, the course could not be significantly restructured for the cluster or the common project. The writing process for this class stayed within the department guidelines of requiring five well developed essays: informative, evaluative, cause and effect, persuasive, and positional. These essays were developed within three areas of the common project.

- Evaluate the consequences of a logging ban.

- Make a recommendation for the "best" solution to the problem.

- Determine public policy regarding whose land it is and who should benefit.

The writing process included pre-writing exercises for discovery, writing drafts, and rewriting drafts. The process also included proofreading, editing, peer review, and conferring with peer 
facilitators and the instructor. Pre-writing included instruction in developing a subject, occasion, audience, and purpose and introducing the topic, restriction of the topic, and illustration of thesis development. Traditional teaching of how to insert supportive material, use facts, statistics, and endorsements or quotes were all discussed in class.

The English class was taught in a computerized classroom. The desk/tables (quads) were in the shape of cross with a computer station on each arm of the cross. Student teams were assigned to each quad. Teaching in a computerized classroom has its unique set of blessings. Since editing, correcting grammar and mechanics, and spell checking become secondary activities, students have more time to concentrate on the writing process. However, at the same time students' focus remains a challenge. No longer is the problem that students are not focused, but rather that they now have new focus: e-mail and the Internet. Allowing students time to check their E-mail or surf the Net prior to class or for an agreed upon time, contributed to being able to redirect their attention at the beginning of a class. Occasional reminders during class were necessary to refocus students' attention on class activities.

Establishing e-mail accounts was important to the success of the class in that during the semester students were able to inquire about information from both instructor and group members. E-mail was essential for reinforcing assignments and making general observations

about completed writing assignments, and for purposes of encouragement to the class as a whole or individually. Students eventually used e-mail to ask questions and converse on a subject. Email contributes tremendously toward establishing a paperless classroom and a 24-hour bulletin board.

In addition to using the supplemental reading material given to the students in the engineering class, students also researched the Internet for more material. In-class research on the Internet followed this procedure: Topics were divided so that each member of the group did different online research and became an advisor/consultant/expert in the area. The following

links in each area were given to assist students in beginning their research.

- Environmental solution

Mendocino County Ecology

Sierra Club

- Economical solution

Timber Production Zone

San Francisco Examiner Economic vs. Ecological Values

- Private industry solution

Pacific Lumber Co.

Charles Hurwitz

Maaxam Co.
- Governmental solution

Rep. Frank Riggs

U.S. Department of Interior

Sen. Dianne Feinstein

Endangered Species Act

- Technological solution

Construction/housing Trends

HUD and the Home Builders Assc.

Popcorn Report

Aluminum products 
Some of these topics delivered students to worthwhile information and others were dead ends. The exercise served to develop lateral thinking and to see multiple sides of the issue.

Once discussion of all the project modules had been completed in the engineering course, the students began writing the briefing paper. The first draft was submitted to the English peer facilitator/tutor for editing and suggestions. Some students submitted more than one draft to the peer facilitator for additional help. The second draft was submitted to the English instructor for her review and comments. The final paper was then submitted to the engineering instructor for grading.

\section{The Math Connection}

The pre-calculus course is modular in design. The four credit course is internally divided into four, one-hour mini-courses. The semester is internally divided into five time intervals. The course meets five days per week. Twelve sections of the course are offered Monday through Friday, six at 8:30 a.m. and six at 10:30 a.m. All four parts of the course are offered at both time slots during each of the five time intervals. Although the five-day per week schedule looks and feels like a five credit course, it is not. Previous examination of student course taking behavior indicated that it took students between four and five time intervals to pass the course. Adding an extra day to the week allows a fifth time interval in the semester and gives students a better chance of completing the course in one semester. Students must pass all four of the mini-courses to pass the course. Students are allowed three tries at each part of the course. Students who pass each of the four parts without failing a part, complete the course before the end of the semester. These students have the option of finishing the course three weeks early or retaking any of the four parts to try to improve their overall grade. Students who do not complete all four modules by the end of the semester receive an "In-Progress" grade and must register for the course the following semester to complete the remaining modules. Students who fail one of the sections three times, receive a failing grade and must repeat the entire course.

During any of the five time intervals (including the first), students will be distributed between all four modules of the course. Students enrolling in the course for the first time or those repeating the course (because they failed a module) will start with module 1 unless they choose to test into a higher module. Students can test into any of the four modules before classes start. Students who are continuing the course from the previous semester start where they left off.

The connection with math on the common project broke down after the first few weeks due to the modular nature of the pre-calculus course. All of the students in the cluster started the precalculus course with module 1 in the first time period. After the first time period, most of the students progressed to module 2 with a few needing to retake module 1 . After the second time period, most of the students progressed to module 3 with the others distributed between modules 1 and 2. Consequently, by the time the common project was implemented in the engineering class, the students were already distributed between two different topic areas in pre-calculus. At the midpoint in the project students were scattered among three math topics. As they began to write the briefing paper, most of the students were completing module 4 with the others scattered 
between modules 2 and 3. As a result, the data analysis that was planned for the math class was abandoned.

\section{OBSERVATIONS AND EXPERIENCES}

The goals of the common project were:

- to strongly link math and English to engineering in the three course cluster,

- to demonstrate the multi-disciplinary nature of real problems,

- to insure that all students understood all of the issues of the project topic,

- to promote critical thinking,

- to improve writing skills,

- to provide students with practical math applications, and

- to demonstrate the importance of written communication in engineering.

All of the goals were met to some degree except strong linking with math and providing practical math applications.

The link with math was weakened significantly because of the modular nature of the precalculus course. Practical math applications through analysis of data from the project was abandoned because students were not all studying the same topics in math at the same time and had different instructors throughout the semester. Practical math applications were covered as a part of problem solving in the engineering course, but were not a part of the common project. One way to partially overcome this problem in the future is to provide a complete set of data for the common project to the math instructors before the semester starts. The math instructors can prepare practical applications for each module of the course in advance. Then, project applications can be used as a normal part of each module. The level of data analysis each student uses in his or her briefing paper will depend on their progress through the four pre-calculus modules. This solution is not perfect, but is the best that is possible with the modular course.

The link between English and engineering was very strong. The English and engineering instructors worked closely together to coordinate their activities. The students gained a good understanding of issues through their reading for and discussions in the engineering class. Their understanding was broadened and gained depth in the English class through their Internet research, analysis of issues and writing. The writing and editing of several drafts of the briefing paper in English markedly improved the depth of the students analysis and the quality of their writing.

The essays and briefing papers created by the cluster students were far superior to those of usual freshman English classes. Students developed a depth on one particular topic, not generally achieved in regular classes. The regular freshman writing program has students writing about their self-image, then evaluating a movie, finding a cause and effect of a problem they see in the community, persuading others to attend this university, and taking a position on a controversial issue of their choice. Most of UTEP's entering students are from the El Paso/Juarez region and 
have very limited outside experience. They generally keep their topic development limited to what they know: their families and their section of the community. Occasionally, a student might write about a historical individual such as Abraham Lincoln rather than a beloved uncle. But, with the national issue of the northwest forests as their primary topic, their world view was broadened to a national, even international, perspective. Students developed strategies, considered solutions and their ramifications, and explored the consequences of all actions and positions.

\section{CLUSTER EVALUATION}

The evaluation of the common project in the Engineering Cluster Program is a portion of the evaluation of the Learning Communities component of the Model Institutions for Excellence initiative at UTEP and the National Learning Communities Dissemination Project (FIPSE Project, The Washington Center). The evaluation is a multi-method effort utilizing a case study approach with multiple measures: surveying and interviewing students, peer faculty and analyzing student outcome data (i.e., GPA as an indicator of success and re-enrollment as an indicator of persistence in school).

What are reported here focuses on the student responses to the common project in one pre-engineering learning community for students who are not calculus ready. Sixteen students (six females, ten males) responded to the 85-item questionnaire that included both force choice items and open-ended items. The questionnaire examined the outcomes from attending the course, personal outcomes, classroom climate, and future plans. In addition, a sample of the students participating in the cluster courses was selected to participate in structured interviews. Results will be reported from an analysis of the questionnaire data assessing outcomes from attending the course, personal outcomes, and classroom climate.

In response to both force choice items and open-ended items, students reported that the common project helped them (1) to understand a problem from multiple perspectives; (2) to work as a group on a project that integrated material and activities from Engineering, Mathematics and English; and (3) to understand the connections between what was learned in the engineering course to what was learned in the mathematics and English course. In addition, students reported that they felt they improved the skills that would lead to success in their course work and in engineering.

Before the project, $73 \%$ of the students reported that they felt "prepared" or "well-prepared" to understand a problem from multiple perspectives. After the project, $94 \%$ reported that they felt "prepared" or "well-prepared." Before the common project, $29 \%$ of the students felt they were "prepared" to work on a project that integrated material and activities from English, mathematics, and engineering courses. After completing the common research paper, $94 \%$ of the students felt they were "prepared". At the outset of the common project, 53\% of the students reported that they felt they had an understanding of the connection between what was learned in an engineering course and what was learned in math and English. After the project, $100 \%$ of the students reported that they were "prepared" or "well-prepared."

$$
-12-
$$


In terms of students' self-assessment of their skill level in the areas of teamwork, research skills, oral communication, written communication, critical thinking/problem solving, social skills and Internet skills at the beginning of the course and before the common project, $13 \%$ to $73 \%$ of the students felt they were "under-prepared" in one or more areas. At the end of the course and the completion of the common project, $93 \%$ of the students felt "prepared" or "well-prepared" in all of the areas.

Activities in the classroom facilitate student success, in general, and specifically the completion of the common project. In order to assess the degree to which activities associated with positive classroom climate occurred, students were asked to rate how often certain activities happened. In general, students reported that the following activities occurred frequently or always: the engineering cluster encouraged dialogue between students and instructors, the engineering cluster valued asking questions and promoted a desire to learn and think critically; the engineering cluster encouraged cooperative effort; the engineering cluster was intellectually challenging and interesting; and the engineering cluster course required involvement in a project in which there was an integration of different disciplines.

One student summed up the value of the common project in the following way:

"When our groups were given a project in which brain-storming to solve a complex problem was required - [it] gave us a chance to work as a team, feel acceptance of peers, and flex our "high cognitive" brain muscle."

In summary, students reported that their participation in the engineering cluster course and completion of the common project provided them with the opportunity to (1) integrate knowledge from multiple disciplines, (2) develop their knowledge, strategies and skills in the academic arena, and (3) develop communication and teamwork skills within a classroom context that fostered a community of learners.

\section{THE FUTURE}

The use of a common project to link math and English to engineering in a three-course cluster for entering pre-engineering students was very successful in spite of the breakdown in the link with math. Plans are underway to expand the use of a common project to four engineering clusters encompassing 200 students in Fall 1998. The link with math will be improved by providing all of the data for common projects to the math instructors in advance so that they can develop practical applications before the semester begins. At least two new common project topics will introduced into these clusters.

A common project will be piloted in Spring 1998 for a second semester cluster consisting of the second English composition course, the second pre-calculus course, and the required Introduction to Engineering course. Students in this cluster will be those who completed the first semester cluster in Fall 1997. The common project topic will be "nuclear energy - blessing or curse?" 
WALTER W. FISHER is a professor of Metallurgical and Materials Engineering at the University of Texas at El Paso. He has more than fifteen years of experience teaching entering engineering students. He is currently responsible for designing and coordinating the introductory engineering courses for the "cluster" program at UTEP.

CONNIE KUBO DELLA-PIANA is an assistant professor in Department of Communication at the University of Texas at El Paso. Her areas of expertise are organizational communication and program evaluation. Currently, she is heading the evaluation of two National Science Foundation systemic reform projects at UTEP, the Model Institutions for Excellence and the Partnership for Excellence in Teacher Education.

CAROL CROWLEY is an instructor in the Department of English at the University of Texas at El Paso. She has several years of experience teaching developmental English, freshman composition, and research and critical writing both at UTEP and the El Paso Community College. 